\title{
PROJETO DE EMBALAGENS PARA PEÇAS DE AUTOMOTIVAS APLICANDO O DESDOBRAMENTO DA FUNÇÃO QUALIDADE (QFD)
}

\section{DESIGN OF PACKAGE FOR AUTOMOBILE PARTS USING QUALITY FUNCTION DEPLOYMENT (QFD)}

\author{
Byanca Porto de Lima ${ }^{1}$; Jorge Muniz Junior ${ }^{2}$; Antonio Wagner Forti ${ }^{3}$ \\ ${ }^{1}$ Universidade de Taubaté - UNITAU - Taubaté - Brasil \\ byanca_porto@yahoo.com.br \\ ${ }^{2}$ Universidade Estadual Paulista - UNESP - Campus de Guaratinguetá - Guaratinguetá - Brazil \\ jorgemuniz@feg.unesp.br \\ ${ }^{3}$ Universidade Estadual Paulista - UNESP - Campus de Guaratinguetá - Guaratinguetá - Brazil \\ awforti@feg.unesp.br
}

\begin{abstract}
Resumo
O objetivo do artigo é analisar a aplicação do Desdobramento da Função Qualidade (QFD) no processo de desenvolvimento de embalagens para transporte e armazenamento de peças utilizadas na linha de montagem de uma montadora de automóveis. Apesar de o QFD ser uma ferramenta muito utilizada no setor automotivo para desenvolvimento de produtos, ela é pouco empregada no desenvolvimento de embalagens. A indústria automotiva avalia as embalagens utilizadas no abastecimento de componentes para a aprovação de novos produtos. Baseado no conhecimento de pessoas de várias áreas, as quais atuam no projeto, desenvolvimento e liberação de embalagens, este estudo indica quais parâmetros são levados em conta e o grau de importância entre as áreas, cita-se: custo, preservação da peça, rastreabilidade, ergonomia e outros. É importante salientar que alguns atrasos na aprovação de protótipos de peças automotivas acontecem, em virtude de problemas com a sua embalagem. Desse modo, o QFD pode contribuir para minimizar esse problema.
\end{abstract}

Palavras-Chave: desenvolvimento de embalagens; engenharia simultânea; montadora de automóveis; QFD.

\section{Introdução}

O método de Desdobramento da Função Qualidade, em inglês, Quality Function Deployment (QFD) tem sido amplamente empregada para desenvolver novos produtos, porém, nota-se que sua utilização tem evoluído de forma eficaz para outros desenvolvimentos, como: serviços (DEROS et al, 2009), processos e outras aplicações não convencionais como: estratégias de marketing e confiabilidade de sistemas entre outras (MEHRJERDI, 2010; ZHANG e CHU, 2009; CHENG e MELO FILHO, 2007; MIGUEL e CARNEVALLI, 2006). 
A aplicação do QFD contribui para o desenvolvimento de novos produtos e serviços, pois auxilia na tradução das necessidades do consumidor em requisitos técnicos de engenharia. O QFD se popularizou no setor automotivo; no entanto, não é comum observar sua utilização no desenvolvimento de dispositivos e equipamentos de apoio à produção, como, por exemplo, embalagens e equipamentos de movimentação.

A indústria automotiva movimenta grande número de componentes, os quais necessitam uma variedade de embalagens. Entretanto, o tratamento para desenvolvimento dessas embalagens não recebe a mesma atenção que os processos e produtos. Essa falta de atenção pode atrasar o lançamento de um produto, pois muitas vezes a análise da embalagem é feita simultaneamente com o recebimento dos protótipos das peças em desenvolvimento e, nesse momento, se mudanças na embalagem forem necessárias, o atraso no lançamento de um novo veículo é inevitável.

O objetivo do artigo é analisar a aplicação do método QFD no processo de desenvolvimento de embalagens numa montadora de automóveis. O estudo é delimitado ao processo de desenvolvimento de embalagens de peças usadas na produção.

Para isso, um novo processo de desenvolvimento de embalagens é proposto, o que contribui para diminuir riscos de alterações da embalagem após a elaboração da protótipo, além do que procura-se diminuir ruídos de comunicação cliente-fornecedor e possibilitar a aprovação da embalagem com maior rapidez e eficácia. Este trabalho pode contribuir também como auxílio didático em aulas relativas aos temas discutidos devido ao detalhamento das etapas descritas no decorrer do trabalho.

Este artigo está estruturado da seguinte forma: Seção 2 apresenta a revisão teórica referente ao QFD. Seção 3 aborda o procedimento metodológico. Seção 4 apresenta o estudo desenvolvido e a análise dos resultados obtidos. Seção 5 discute as conclusão e considerações do estudo realizado.

\section{Revisão teórica}

Dentre os principais métodos que dão suporte aos processos de projeto colaborativo, garantindo uma melhor qualidade aos produtos/serviços podem ser citados: o Desdobramento da Função Qualidade, em inglês, Quality Function Deployment (QFD), o FMEA (Análise dos Modos e Efeitos de Falha de Produto, em inglês, Failure Mode and Effect Analysis), que são utilizados para transferir e satisfazer os desejos e requisitos do consumidor em todas as fases do desenvolvimento (BADIN, 2005).

Existe uma vasta literatura sobre QFD, relatando a sua história e as suas amplas aplicações. Trabalhos como o de Mehrjerdi (2010) e Chan e Wu (2002) fazem um amplo levantamento teórico e histórico sobre o assunto e evidenciam a força do método pelas suas amplas aplicações em desenvolvimento do produto, gestão da qualidade, análise das necessidades dos clientes, projeto do 
produto, planejamento, tomada de decisão, gestão e relacionamento com trabalho em equipe, tempo e custo.

Eventualmente o QFD tem avançado com aplicações setores de serviço tais como governo, bancos, saúde e educação. Na indústria dificilmente se acham exemplos no qual o QFD não tenha sido usado (CHAN e WU, 2002).

O QFD é um dos métodos mais utilizados na Engenharia Simultânea, pois de forma sistêmica, traduz as necessidades e expectativas dos consumidores. São utilizadas matrizes (Figura 1) para integrar e desdobrar as informações técnicas traduzidas das necessidades dos clientes até a entrega do produto; são estabelecidos valores a estas necessidades, que são transformadas em características de qualidade no projeto, produção e no processo de manufatura (WHEELWRIGHT; CLARK, 1992).

Figura 1 - Os elementos da Casa da Qualidade

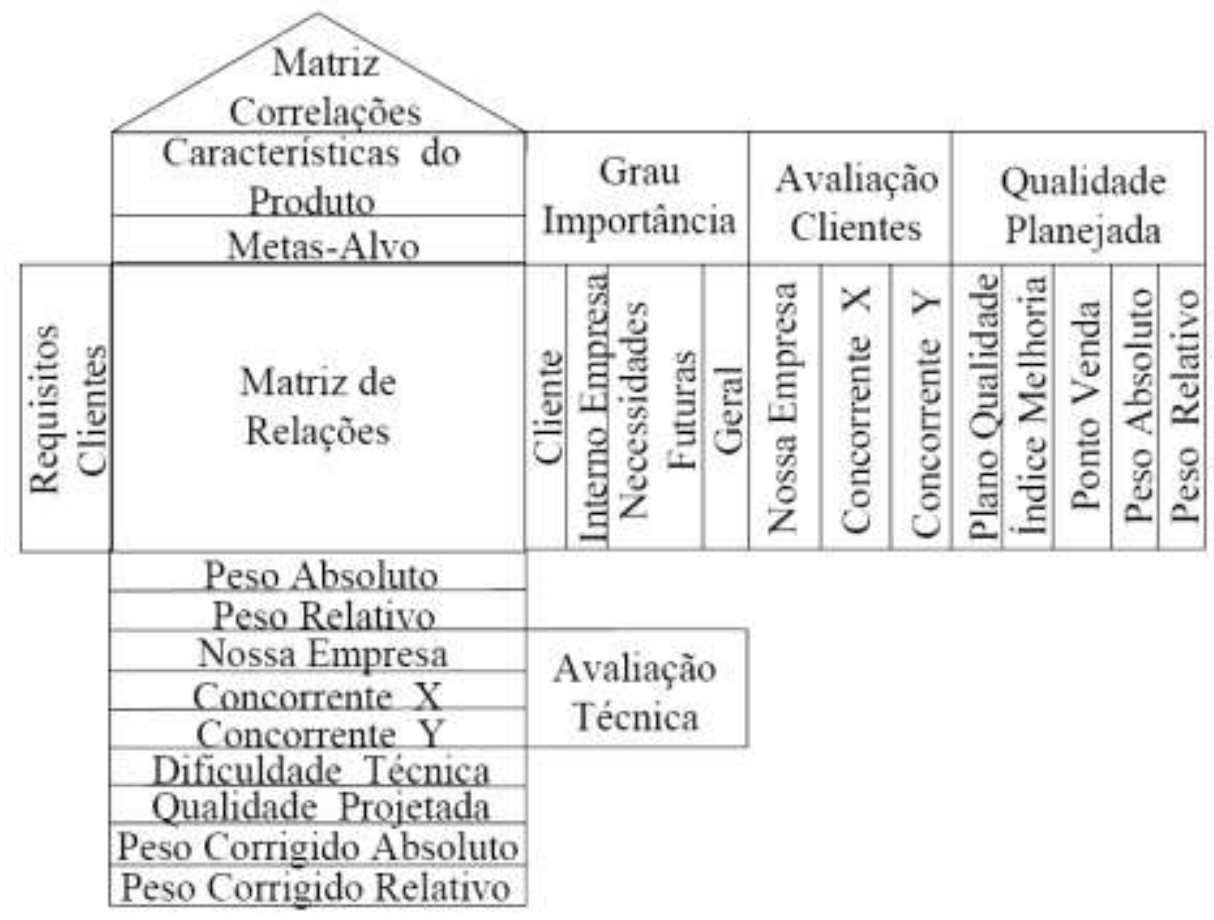

Fonte: Otelino (1999)

A partir do trabalho de Akao (1990), surgiram variações do modelo original desenvolvido pelo autor. Essas variações mantêm as características principais, mas apresentam modificações, principalmente com relação aos desdobramentos. Dentre as variações existentes, pode-se destacar:

- O QFD das quatro fases e o QFD estendido (MIGUEL, 2008).

- QFD das Quatro Fases (Sullivan, 1986; Hauser e Clausing, 1988). Consiste em desdobramentos sucessivos a partir do planejamento do produto, dos componentes, planejamento do processo, além da produção.

- QFD-Estendido, tendo como base o QFD das quatro fases. Esse modelo é considerado “estendido", pois inclui tomada de decisão no processo de desenvolvimento de produto, por meio da 
aplicação do processo de seleção de conceitos de Pugh (1991). O desdobramento do produto também é incluído em diversos níveis de agregação: sistema total, sistema, subsistema e componentes.

O QFD também é um método de solução de problemas, pois lista o quê precisa ser feito e como pode ser feito.

Ribeiro et al (2001) elaborou uma abordagem do QFD para aplicação no setor de serviços, a partir da abordagem de Akao, partindo de uma pesquisa com os clientes. O Método recomendado para serviços utiliza três matrizes principais: Matriz da Qualidade, Matriz dos Serviços e Matriz dos Recursos.

No presente trabalho, foi utilizada uma adaptação da Matriz de Qualidade de Ribeiro et al (2001), a qual é detalhada na seção 4: Aplicação do QFD para desenvolvimento de embalagem.

A embalagem é um item importante para logística, pois influencia a disponibilização as mercadorias no tempo certo, nas condições adequadas e com o menor custo possível.

Embalagens são invólucros, recipientes ou qualquer forma de acondicionamento removível, ou não, destinado a cobrir, empacotar, envasar, proteger, manter os produtos, ou facilitar a sua comercialização. (GURGEL, 2007). Também pode ser entendida como um sistema integrado de materiais e equipamentos, utilizado para levar produtos ao cliente, por meio de canais de distribuição.

Algumas razões para as despesas com embalagens são: facilitar a estocagem e o manuseio, melhorar a utilização dos equipamentos de transporte, fornecer proteção a produto, promover a venda de produtos, facilitar o uso de produtos, fornecer valor de reutilização de produtos (BALLOU, 2001).

Conforme a NBR ISO 9001:2008; itens 7.5.5 (ABNT, 2008), a organização deve preservar o produto durante o processamento interno e a entrega no destino pretendido. Quando aplicável, a preservação deve incluir identificação, manuseio, embalagem, armazenamento e proteção. A preservação também deve ser aplicada às partes constituintes de um produto.

O desenvolvimento de embalagem requer trabalho de áreas distintas na busca de uma melhor solução: industrial, engenharia, segurança do trabalho. O enfoque de Engenharia Simultânea (E.S.) contribui nessa busca.

Engenharia Simultânea é o processo em que grupos interfuncionais trabalham de forma interativa e formal no projeto de ciclo de vida completo do produto/serviço para encontrar e realizar a melhor combinação entre as metas de qualidade, custo e prazo (MUNIZ, 1996).

Um ponto marcante na E.S. é o trabalho de grupos interfuncionais, que promove uma sinergia criativa e benéfica para o desenvolvimento de produtos, pois por meio disso é criada uma co-responsabilidade entre seus membros, em alguns casos fornecedores, sobre as decisões tomadas. 
Dentre essas, muitas decisões são potencializadas pelo uso de técnicas adequadas, consenso e constante troca de informações atualizadas e precisas durante todas as etapas do desenvolvimento de um produto.

\section{Procedimento metodológico}

Nesta seção serão apresentadas a classificação do método de pesquisa, descrição da empresa pesquisada e o "passo a passo" de aplicação da matriz de qualidade, o qual emprega o método de Ribeiro et al (2001).

\subsection{Classificação do método}

Este trabalho é classificado como qualitativo, pois as avaliações e discussões são subjetivas e baseadas na interpretação dos fatos específicos. Quanto ao objetivo, este pode ser classificado como exploratório, busca-se uma melhor compreensão de um problema específico ligado à área de desenvolvimento de embalagens de uma montadora de automóveis.

O problema investigado é conduzido pela primeira autora. A mesma atuou no planejamento e controle do desenvolvimento e melhoria de produtos, tendo contato direto com o setor de desenvolvimento de embalagens e demais setores envolvidos (custos, engenharia de produto, qualidade, engenharia de processo, etc.).

A pesquisa foi realizada em uma montadora de automóveis de origem francesa que utiliza e movimenta quase quinze mil tipos de embalagens, necessárias para produzir centenas de carros por dia. Nessa montadora, o desenvolvimento de embalagens é feito em conjunto com os fornecedores.

Durante o processo de definição de fornecedores, o desenvolvimento de embalagens tem relação direta com a garantia da integridade da peça, desde o processo de fabricação até a montagem na linha de veículos. A embalagem, desde o seu estudo preliminar até a sua aprovação, passa por diversas áreas, por exemplo: logística, produção, engenharia de produto.

\subsection{Etapas do método}

Os passos para o desenvolvimento da matriz de qualidade foram organizadas da seguinte forma.

- $1^{\circ}$ Passo: Identificação das etapas no processo de desenvolvimento de embalagens prever e atribuir responsabilidades dos clientes e fornecedores envolvidos, sejam eles internos ou externos. Essas etapas variam de empresa para empresa.

- 20 Passo: Definição da equipe QFD - escolher representantes de áreas envolvidas na aprovação da embalagem. No caso desenvolvido a equipe foi formada por profissionais das 
seguintes áreas: PCP, Manufatura, Processo, Produto, Qualidade, Segurança de Trabalho e Ergonomia, Desenvolvimento de Embalagens e por um Fornecedor de autopeças.

- $3^{\circ}$ Passo: Treinamento da equipe - apresentar o conceito, os benefícios e o detalhamento das etapas do método QFD.

- $4^{\circ}$ Passo: Identificação dos requisitos de qualidade ou qualidades demandadas identificar os requisitos de qualidade relacionados às áreas envolvidas utilizando questõesorientativas numa sessão de brainstorming, por exemplo:

a) "Quais as características que você julga importante numa embalagem?"

b) "O que você avalia na embalagem no processo de aprovação?”.

- $5^{\circ}$ Passo: Classificação dos requisitos de qualidade demandados - organizar um diagrama de árvore, desdobrando em requisitos primários e secundários (Quadro 01), o que permite a obtenção do grau de importância detalhado de cada item.

\begin{tabular}{|c|c|}
\multicolumn{2}{c}{ Quadro 01 - Diagrama de árvore } \\
\hline Requisitos Primário & Requisitos Secundário \\
\hline \multirow{2}{*}{1} & 1.1 \\
\cline { 2 - 2 } & 1.2 \\
\hline
\end{tabular}

Fonte: Cheng (1995)

- $6^{\circ}$ Passo: Definição da Importância da Qualidade Demandada (IDi) - atribuir a importância dos itens de Qualidade Demandada (IDi) na opinião dos representantes das áreas que definiram os requisitos de qualidade. Foi utilizada a escala de pontuação apresentada no Quadro 02 para cada requisito. O grau de importância da qualidade demandada, inserido na matriz de qualidade, foi calculado por meio da média aritmética de todas as pontuações obtidas.

Quadro 02 - Escala de importância da qualidade demandada

\begin{tabular}{|c|c|}
\hline Grau de Importância & Escala \\
\hline Muito Importante & 2,0 \\
\hline Importante & 1,0 \\
\hline Pouco Importante & 0,5 \\
\hline
\end{tabular}

Fonte: Ribeiro et al (2001)

- $7^{\circ}$ Passo: Desdobramento das características de qualidade - detalhar e definir características de qualidade demandada. Elas são dispostas na parte superior da matriz da qualidade.

- $\quad 8^{\circ}$ Passo: Estabelecimento do grau de relacionamento entre os requisitos de qualidade e as características de qualidade - preencher a matriz da qualidade. Os itens da qualidade demandada são cruzados com os itens das características de qualidade e são estabelecidas as intensidades dos relacionamentos. A intensidade do relacionamento entre os itens da qualidade demandada e das características de qualidade (DQij) podem ser relações fortes, médias e fracas (Quadro 03).

O relacionamento é feito respondendo a seguinte questão: se a uma determinada característica da qualidade $\mathrm{X}$ for mantida em níveis excelentes, estará assegurada a satisfação da 
qualidade demandada Y? Se a resposta for sim, então a relação é forte; se a resposta for parcialmente, então a relação é média e assim por diante.

Quadro 03 - Escala de relacionamento da qualidade demandada com as características de qualidade (DQij).

\begin{tabular}{|c|c|}
\hline Relacionamento & Peso \\
\hline Forte & 9 \\
\hline Médio & 3 \\
\hline Fraco & 1 \\
\hline
\end{tabular}

Fonte: Mizuno \& Akao (1994) apud Ribeiro et al (2001)

- $9^{\circ}$ Passo: Definição da Importância das Características de Qualidade (IQj) - considerar os relacionamentos que as características de qualidade mantém com os itens da qualidade demandada e também a importância relativa desses últimos. A fórmula (Equação 01) proposta por Ribeiro et al (2001) não possui unidade de medida.

$$
I Q_{j}=\sum_{i=1}^{n} I D_{i} * D Q_{i j}
$$

Sendo:

$I Q_{j}=$ Importância das características de qualidade (importância técnica)

$I D_{i}=$ Importância da qualidade demandada

$D Q_{i j}=$ Intensidade do relacionamento entre os itens da qualidade demandada e das características de qualidade.

- $10^{\circ}$ Passo: Definição do Grau de Dificuldade (Dj), avaliar a dificuldade de se modificar as especificações das características de qualidade utilizando o Quadro 04. Nota-se que quanto mais fácil é agir sobre a característica de qualidade, maior é a pontuação. Isto ocorre porque são priorizadas as características que são mais fáceis de serem modificadas/ alcançadas.

Quadro 04 - Escala de avaliação da dificuldade de atuação sobre as características de qualidade Dj.

\begin{tabular}{|c|c|}
\hline \multicolumn{2}{|c|}{ Escala de Importância } \\
\hline Dificuldade & Escala \\
\hline Muito Difícil & 0,5 \\
\hline Difícil & 1,0 \\
\hline Moderado & 1,5 \\
\hline Fraco & 2,0 \\
\hline
\end{tabular}

Fonte: Ribeiro et al (2001)

- 11․ Passo: Priorização das Características de Qualidade (IQj*) - calcular o índice de importância corrigido. Esse índice é calculado considerando a importância das características de qualidade e a dificuldade de atuação sobre as mesmas. Com este índice pode-se identificar as características de qualidade que terão maior impacto sobre a satisfação dos clientes. 
Assim, a priorização é feita com base no índice de importância corrigido (IQj*), o qual é calculado por meio da Equação (02) proposta por Ribeiro et al. (2001).

$$
I Q_{J}^{*}=I Q_{j} \sqrt{D_{j}}
$$

Sendo:

$I Q_{J}^{*}$ - Importância corrigida das características de qualidade;

$I Q_{j}$ - Importância das características de qualidade (importância técnica);

$D_{j}$ - Avaliação da dificuldade de atuação.

\section{Aplicação do QFD para desenvolvimento de embalagem}

Os requisitos de qualidade dos clientes internos (qualidade demandada) do setor de desenvolvimento de embalagens é apresentado no Quadro 05.

Quadro 05 - Requisitos de Qualidade e Definições

\begin{tabular}{|c|c|}
\hline Requisitos de Qualidade & Definição \\
\hline $\begin{array}{l}\text { Conservar a integridade do } \\
\text { produto }\end{array}$ & $\begin{array}{l}\text { Manter as características dimensionais e funcionais do produto } \\
\text { acondicionado. }\end{array}$ \\
\hline $\begin{array}{l}\text { Evitar lesões nas mãos no } \\
\text { manuseio da embalagem }\end{array}$ & $\begin{array}{l}\text { Evitar danos físicos durante o manuseio da embalagem (provocado por } \\
\text { arestas cortantes) }\end{array}$ \\
\hline Evitar lesões físicas & $\begin{array}{c}\text { Atender as condições de Ergonomia (embalagem no peso adequado, com } \\
\text { alça para facilitar o operador pegar a embalagem) }\end{array}$ \\
\hline $\begin{array}{l}\text { Não interferir na rentabilidade da } \\
\text { autopeça do novo fornecedor }\end{array}$ & $\begin{array}{l}\text { Minimizar o custo da embalagem, pois o preço da embalagem é } \\
\text { considerado no estudo de rentabilidade inicial. }\end{array}$ \\
\hline Ter baixo custo de manutenção & $\begin{array}{l}\text { Minimizar itens sujeitos a manutenção, tais como: rolamento, mola, etc. É } \\
\text { um requisito específico para embalagem retornável. }\end{array}$ \\
\hline Ser desmontáveis ou dobráveis & $\begin{array}{c}\text { Procurar desenvolver embalagens que possam ser dobráveis ou } \\
\text { desmontáveis para minimizar o custo com o transporte, pois é necessário } \\
\text { minimizar o espaço de ocupação. }\end{array}$ \\
\hline $\begin{array}{l}\text { Acondicionar o maior número de } \\
\text { peças possível. }\end{array}$ & $\begin{array}{l}\text { Reduzir a quantidade de vezes por turno que o operador necessitará fazer } \\
\text { reabastecimentos de linha. }\end{array}$ \\
\hline Ser empilhável & $\begin{array}{c}\text { Manter configuração estável de armazenamento e movimentação com } \\
\text { empilhadeira (aproveitamento vertical) }\end{array}$ \\
\hline Facilitar a retirada das peças & $\begin{array}{c}\text { Desempacotar com e rapidez e facilidade, por exemplo: a embalagem } \\
\text { descartável precisa vim com tampa, caso contrário, será necessário o uso } \\
\text { de um estilete para retirar as peças }\end{array}$ \\
\hline Identificar corretamente & $\begin{array}{l}\text { Identificar as características do produto embalado, por exemplo código de } \\
\text { barras, peso, numero de caixas que podem ser empilháveis. }\end{array}$ \\
\hline $\begin{array}{l}\text { "Não acumular água ou } \\
\text { resíduos" }\end{array}$ & $\begin{array}{l}\text { Permitir escoamento de líquidos. Toda embalagem, antes de seu } \\
\text { carregamento, precisa estar vazia e livre de qualquer impureza. }\end{array}$ \\
\hline
\end{tabular}

Fonte: Autoria própria (2011)

Baseado no Quadro 05, as áreas que aprovam a embalagem (os clientes internos), atribuíram a pontuação a estes requisitos de qualidade de acordo com o grau de importância julgado por eles. Os requisitos de qualidade e a média aritmética de todas as pontuações que determinaram a importância de cada requisito foi disposta na Tabela 01 . 
Tabela 01 - Pontuações atribuídas aos requisitos de qualidade

\begin{tabular}{c|c|c|c|c|c|c|c}
\hline $\begin{array}{c}\text { Qualidade Demandada ou } \\
\text { Requisitos de Qualidade }\end{array}$ & $\begin{array}{c}\text { Média do Grau } \\
\text { de Importância } \\
\text { (IDi) }\end{array}$ & PCP & Manuf. & Processo & Qualid. & $\begin{array}{c}\text { Segurança } \\
\text { de } \\
\text { Trabalho }\end{array}$ & Ergonomia \\
\hline $\begin{array}{c}\text { Conservar a integridade do } \\
\text { produto }\end{array}$ & 2,0 & 2 & 2 & 2 & 2 & 2 & 2 \\
\hline $\begin{array}{c}\text { Evitar lesões nas mãos no } \\
\text { manuseio da embalagem }\end{array}$ & 1,7 & 1 & 2 & 2 & 1 & 2 & 2 \\
\hline Evitar lesões físicas & 1,6 & 0,5 & 2 & 2 & 1 & 2 & 2 \\
\hline $\begin{array}{c}\text { Manter rentabilidade da } \\
\text { autopeça do novo fornecedor }\end{array}$ & 1,0 & 1 & 1 & 1 & 1 & 1 & 1 \\
\hline $\begin{array}{c}\text { Ter baixo custo de } \\
\text { manutenção }\end{array}$ & 1,0 & 1 & 1 & 1 & 1 & 1 & 1 \\
\hline $\begin{array}{c}\text { Ser desmontáveis ou } \\
\text { dobráveis }\end{array}$ & 0,8 & 1 & 1 & 1 & 0,5 & 0,5 & 0,5 \\
\hline $\begin{array}{c}\text { Acondicionar o maior número } \\
\text { de peças possível. }\end{array}$ & 0,8 & 1 & 1 & 1 & 1 & 0,5 & 0,5 \\
\hline $\begin{array}{c}\text { Ser empilhável } \\
\text { (aproveitamento vertical) }\end{array}$ & 1,3 & 2 & 2 & 1 & 1 & 1 & 1 \\
\hline $\begin{array}{c}\text { Facilitar a retirada das peças } \\
\text { Identificar corretamente }\end{array}$ & 1,0 & 2 & 2 & 0,5 & 0,5 & 0,5 & 0,5 \\
\hline $\begin{array}{c}\text { Não acumular água ou } \\
\text { resíduos }\end{array}$ & 0,6 & 0,5 & 0,5 & 0,5 & 1 & 0,5 & 0,5 \\
\hline Fonos & 1,0 & 2 & 2 & 0,5 & 0,5 & 0,5 & 0,5 \\
\hline
\end{tabular}

Fonte: Pesquisa de campo (2012)

A Figura 2 apresenta a organização da média aritmética do grau de importância de cada requisito em ordem decrescente.

Figura 2 - Requisitos de Qualidade em ordem decrescente

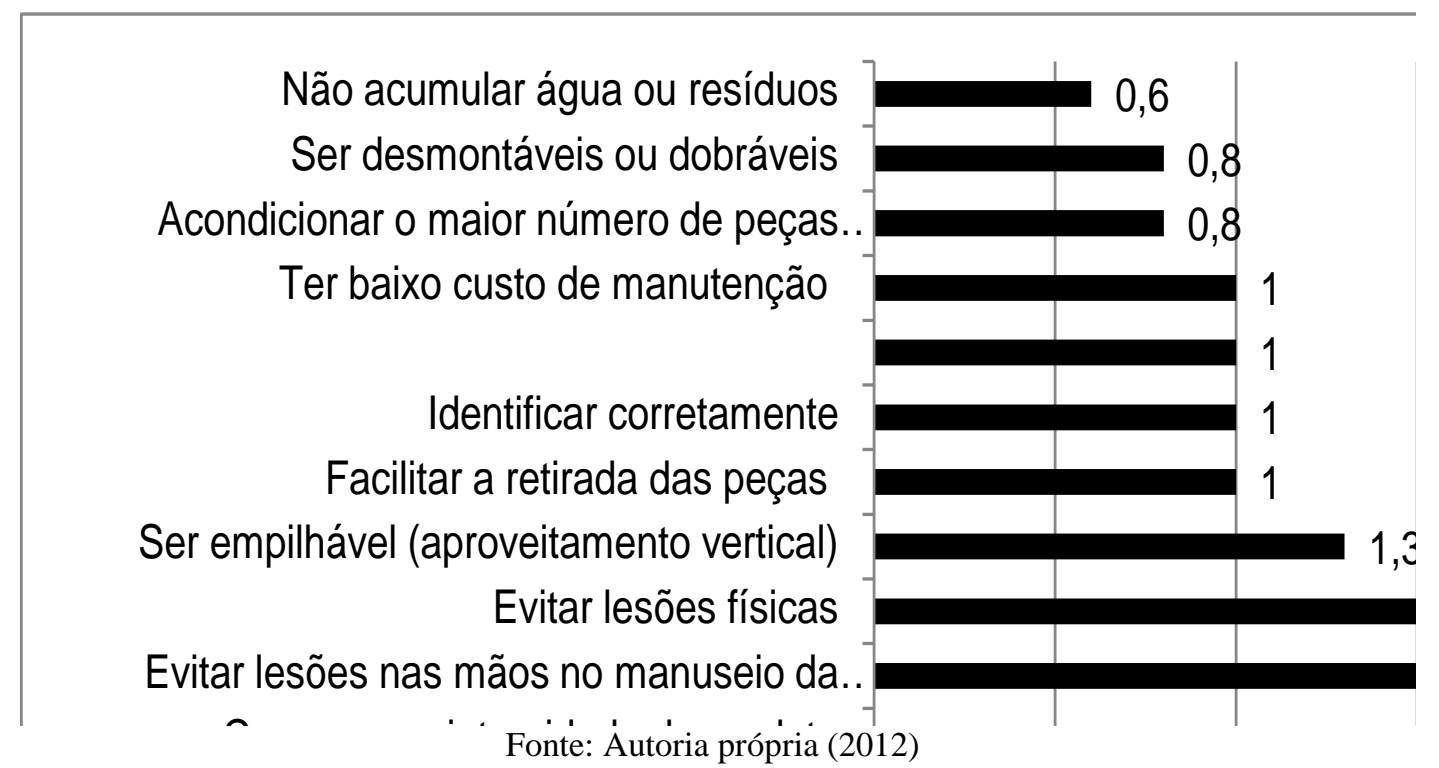

O requisito de qualidade "conservar a integridade do produto" é classificado por Kano et al (1984) como um "requisito esperado" pois quando incorporado na embalagem, constitui uma presença óbvia, porém, a sua ausência provoca insatisfação. Como garantir a integridade de produto é uma função básica da embalagem, foi o requisito mais importante informado pelas áreas. Se não for considerado este requisito no desenvolvimento de embalagens, os clientes internos se sentirão insatisfeito. 
Foi observada uma preocupação com a ergonomia pelos clientes internos, pois segundo os envolvidos, esta é uma das principais causas de correções em embalagens recém-desenvolvidas.

"Não interferir na rentabilidade da autopeça" foi um item que obteve uma importância intermediária, porque nenhuma destas áreas possui ligação com o setor de custos, porém, deve-se registrar que este resultado condiz com o objetivo desta etapa do método, pois se buscaram os requisitos de qualidade mais importantes para as áreas. Em relação aos aspectos de custo, depois de definidas as características de qualidade que atendem as estes requisitos de qualidade, é verificado se todos eles poderão ser atendidos. Isto dependerá dos impactos destes requisitos na viabilidade econômica da embalagem.

As características de qualidade foram desdobradas pela equipe QFD em conjunto com os representantes das áreas que aprovam a embalagem, obtendo-se o Quadro 06.

Quadro 06 - Características de Qualidade Desdobradas pela equipe

\begin{tabular}{|c|c|}
\hline Qualidade Demandada & Característica de Qualidade \\
\hline $\begin{array}{c}\text { Conservar a integridade do produto } \\
\text { Evitar lesões nas mãos no manuseio da } \\
\text { embalagem } \\
\text { Evitar lesões físicas } \\
\text { Não interferir na rentabilidade da } \\
\text { autopeça do novo fornecedor } \\
\text { Ter baixo custo de manutenção } \\
\text { Ser desmontáveis ou dobráveis } \\
\text { Acondicionar o maior número de peças } \\
\text { possível. } \\
\text { Ser empilhável } \\
\text { Facilitar a retirada das peças } \\
\text { Identificar corretamente } \\
\text { Não acumular água ou resíduos }\end{array}$ & $\begin{array}{c}\text { - Diminuir a quantidade de acessórios } \\
\text { - Prover rentabilidade do desenvolvimento do fornecedor de } \\
\text { autopeça } \\
\text { - Manter dimensões conforme desenho } \\
\text { - Estar livre de rebarbas, arestas cortantes ou qualquer elemento } \\
\text { que possa provocar acidente durante o manuseio; } \\
\text { - Prover design ergonômico; } \\
\text { - Ter resistência; } \\
\text { - Utilizar material de qualidade certificada; } \\
\text { - Maximizar a quantidade de peças por embalagem; } \\
\text { - Evitar contato entre as peças; } \\
\text { - Não apoiar partes usinadas e sensíveis das peças diretamente na } \\
\text { embalagem; } \\
\text { - Identificar claramente os dados da embalagem (Código de } \\
\text { Identificação e no de série) }\end{array}$ \\
\hline
\end{tabular}

Fonte: Autoria própria (2012)

As características de qualidade desdobradas e as respectivas definições são apresentadas no Quadro 07.

Quadro 07 - Definições das Características de Qualidade

\begin{tabular}{|c|c|}
\hline Características de Qualidade & Definições \\
\hline Diminuir a quantidade de acessórios & $\begin{array}{l}\text { Minimizar a quantidade de acessórios (fita de arquear, saco } \\
\text { plástico, divisórias, cantoneiras). }\end{array}$ \\
\hline $\begin{array}{c}\text { Prover rentabilidade do } \\
\text { desenvolvimento do fornecedor de } \\
\text { autopeça }\end{array}$ & Minimizar o custo \\
\hline Manter dimensões conforme desenho & Garantir dimensões definidas no desenho \\
\hline $\begin{array}{c}\text { Estar livre de rebarbas, arestas cortantes } \\
\text { ou qualquer elemento que possa } \\
\text { provocar acidente durante o manuseio }\end{array}$ & $\begin{array}{c}\text { Eliminar rebarbas e arestas cortantes da embalagem para garantir a } \\
\text { segurança do operador no manuseio da embalagem }\end{array}$ \\
\hline Prover design ergonômico & Seguir as normas de ergonomia da empresa \\
\hline Ter resistência & Manter características durante o transporte \\
\hline $\begin{array}{l}\text { Utilizar material de qualidade } \\
\text { certificada }\end{array}$ & $\begin{array}{l}\text { Garantir o cumprimento da especificação da embalagem } \\
\text { (resistência, fumigação, caso seja de madeira). }\end{array}$ \\
\hline
\end{tabular}




\begin{tabular}{|c|c|}
\hline $\begin{array}{c}\text { Maximizar a quantidade de peças por } \\
\text { embalagem }\end{array}$ & $\begin{array}{l}\text { Maximizar a quantidade de peças por embalagem (a linha precisará } \\
\text { ser abastecida menos vezes) para minimizar custo de transporte }\end{array}$ \\
\hline Evitar contato entre as peças & Evitar o contato entre que possam danificá-las \\
\hline $\begin{array}{l}\text { Não apoiar partes usinadas e sensíveis } \\
\text { das peças diretamente na embalagem }\end{array}$ & $\begin{array}{c}\text { Não apoiar partes usinadas e sensíveis das peças diretamente na } \\
\text { embalagem }\end{array}$ \\
\hline $\begin{array}{l}\text { Identificar claramente os dados da } \\
\text { embalagem }\end{array}$ & $\begin{array}{c}\text { O código de identificação da peça e o número de série deverão ficar } \\
\text { num local de fácil visualização para o operador. }\end{array}$ \\
\hline
\end{tabular}

Fonte: Autoria própria (2012)

A Qualidade Demandada ou Requisitos de Qualidade foram inseridos nas linhas no lado esquerdo da Matriz de Qualidade e as Características de Qualidade foram organizadas na parte superior da Matriz de Qualidade para a obtenção do grau de relacionamento entre eles, conforme Quadro 08.

Após a definição do grau de importância de cada característica de qualidade, determinação do grau de dificuldade de atuação sobre cada característica, foi realizada a priorização das características de qualidade que precisam ser consideradas na definição de novas embalagens. $\mathrm{O}$ resultado pode ser visto na Matriz da Qualidade (Tabela 02).

Quadro 08 - Grau de relacionamento entre os requisitos de qualidade e as características de qualidade

\begin{tabular}{|c|c|c|c|c|c|c|c|c|c|c|c|}
\hline Característica de Qualidade & 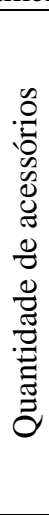 & 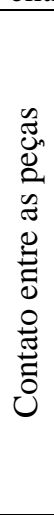 & 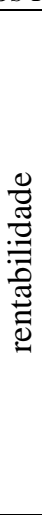 & 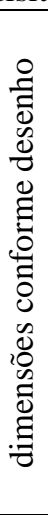 & 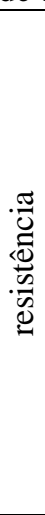 & 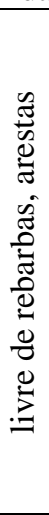 & 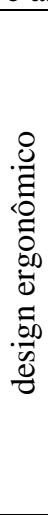 & 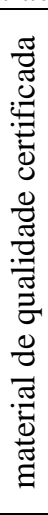 & 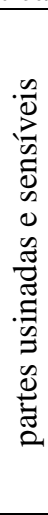 & 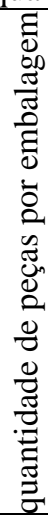 & 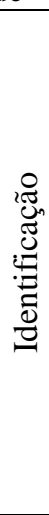 \\
\hline rentabilidade da autopeça & 9 & 1 & 9 & 1 & 1 & 1 & 1 & 1 & 1 & 9 & 1 \\
\hline baixo custo de manutenção & 9 & 1 & 9 & 1 & 9 & 1 & 1 & 1 & 1 & 1 & 1 \\
\hline Lesões nas mãos & 3 & 1 & 1 & 3 & 3 & 9 & 9 & 3 & 1 & 1 & 1 \\
\hline Lesões físicas & 3 & 1 & 1 & 3 & 1 & 9 & 9 & 1 & 1 & 1 & 1 \\
\hline Acúmulo de água ou resíduos & 1 & 1 & 1 & 3 & 1 & 3 & 3 & 1 & 1 & 1 & 1 \\
\hline desmontáveis ou dobráveis & 3 & 1 & 9 & 3 & 3 & 1 & 1 & 3 & 1 & 1 & 1 \\
\hline número de peças & 1 & 1 & 9 & 1 & 1 & 1 & 1 & 1 & 1 & 9 & 1 \\
\hline integridade do produto & 3 & 9 & 1 & 9 & 3 & 3 & 1 & 9 & 9 & 1 & 1 \\
\hline Empilhamento & 3 & 9 & 9 & 3 & 9 & 1 & 1 & 3 & 1 & 1 & 1 \\
\hline Descarregamento & 9 & 1 & 3 & 1 & 1 & 3 & 3 & 1 & 1 & 1 & 1 \\
\hline Identificação & 1 & 1 & 1 & 1 & 1 & 1 & 1 & 1 & 1 & 1 & 9 \\
\hline
\end{tabular}

Fonte: Autoria própria (2012) 
Tabela 02 - Matriz da Qualidade

\begin{tabular}{|c|c|c|c|c|c|c|c|c|c|c|c|c|}
\hline Requisitos de Qualidade & 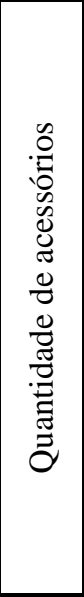 & 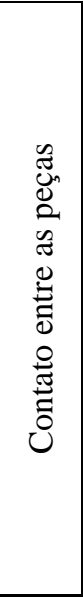 & 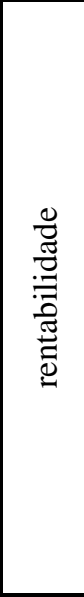 & 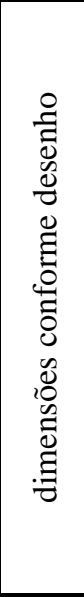 & 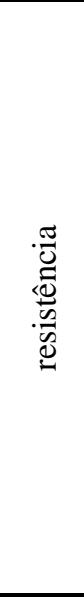 & 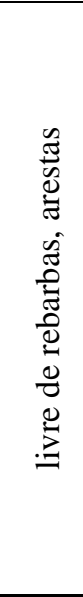 & 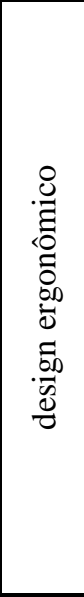 & 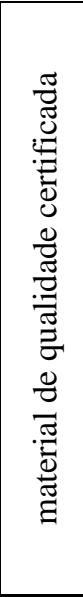 & 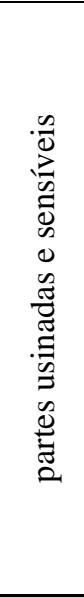 & 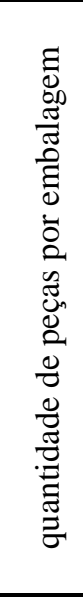 & 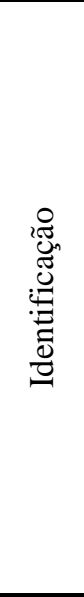 & 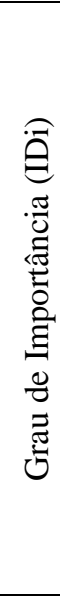 \\
\hline rentabilidade da autopeça & 9 & 1 & 9 & 1 & 1 & 1 & 1 & 1 & 1 & 9 & 1 & 1,0 \\
\hline $\begin{array}{l}\text { baixo custo de } \\
\text { manutenção }\end{array}$ & 9 & 1 & 9 & 1 & 9 & 1 & 1 & 1 & 1 & 1 & 1 & 1,0 \\
\hline Lesões nas mãos & 3 & 1 & 1 & 3 & 3 & 9 & 9 & 3 & 1 & 1 & 1 & 1,7 \\
\hline Lesões físicas & 3 & 1 & 1 & 3 & 1 & 9 & 9 & 1 & 1 & 1 & 1 & 1,6 \\
\hline $\begin{array}{l}\text { Acúmulo de água ou } \\
\text { resíduos }\end{array}$ & 1 & 1 & 1 & 3 & 1 & 3 & 3 & 1 & 1 & 1 & 1 & 0,6 \\
\hline $\begin{array}{c}\text { desmontáveis ou } \\
\text { dobráveis }\end{array}$ & 3 & 1 & 9 & 3 & 3 & 1 & 1 & 3 & 1 & 1 & 1 & 0,8 \\
\hline número de peças & 1 & 1 & 9 & 1 & 1 & 1 & 1 & 1 & 1 & 9 & 1 & 0,8 \\
\hline integridade do produto & 3 & 9 & 1 & 9 & 3 & 3 & 1 & 9 & 9 & 1 & 1 & 2,0 \\
\hline Empilhamento & 3 & 9 & 9 & 3 & 9 & 1 & 1 & 3 & 1 & 1 & 1 & 1,3 \\
\hline Descarregamento & 9 & 1 & 3 & 1 & 1 & 3 & 3 & 1 & 1 & 1 & 1 & 1,0 \\
\hline Identificação & 1 & 1 & 1 & 1 & 1 & 1 & 1 & 1 & 1 & 1 & 9 & 1,0 \\
\hline $\begin{array}{c}\text { Importância das } \\
\text { características de } \\
\text { qualidade } \\
\end{array}$ & 51,4 & 39,4 & 54,1 & 40,6 & 40,3 & 45,9 & 41,9 & 36,3 & 28,8 & 27,4 & 20,8 & \\
\hline Grau de Dificuldade & 1,5 & 2 & 1 & 1,5 & 1,5 & 1 & 1 & 1 & 1,5 & 1,5 & 2 & \\
\hline $\begin{array}{c}\text { Priorização } \\
\text { das características de } \\
\text { qualidade }\end{array}$ & 63,0 & 55,7 & 54,1 & 49,7 & 49,3 & 45,9 & 41,9 & 36,3 & 35,2 & 33,6 & 29,3 & \\
\hline
\end{tabular}

Fonte: Autoria própria (2012)

As características de qualidade de maior prioridade foram: "diminuir a quantidade de acessórios", "impedir o contato entre as peças", "não interferir na rentabilidade da autopeça do novo fornecedor", "ter dimensões conforme desenho", "resistência", "ser livres de rebarbas, arestas cortantes ou qualquer elemento que possa provocar acidente durante o manuseio" e "ter design ergonômico".

Estas características de qualidade foram as mais priorizadas por possuírem um grau de relacionamento muito forte com os requisitos de qualidade mais importantes e por possuírem um grau de dificuldade menor de serem atendidas facilmente atendidas pelos fornecedores em geral.

Convém ressaltar que, após classificar estas características de qualidade em ordem decrescente de importância, é verificada a viabilidade econômica da embalagem. No processo de cotação da 
autopeça, o fornecedor nacional envia sua proposta comercial com o preço estimado de embalagem incluso no preço-peça. Desta forma, o preço da embalagem não pode ultrapassar a estimativa feita no início do desenvolvimento.

Em relação aos benefícios encontrados com a aplicação do método no desenvolvimento de embalagens os principais são: redução da necessidade de realização de modificações na embalagem após a submissão da aprovação da embalagem protótipo, o aumento da satisfação dos clientes internos, a melhoria da comunicação entre os setores envolvidos na aprovação da embalagem e o fornecedor.

\section{Conclusão}

A Matriz da Qualidade, aplicada no desenvolvimento de embalagens, propiciou a interpretação das necessidades dos clientes internos, ligados ao setor de desenvolvimento de embalagens da empresa, e transformá-las em informações sobre as características de qualidade desejadas.

Com a aplicação do método QFD em embalagens de autopeças foi possível identificar aspectos importantes relativo à embalagem que normalmente não são considerados na fase de definição da embalagem, o que ocasionava constantes atrasos no cronograma de nacionalização das autopeças devido à necessidade de alterações na embalagem protótipo.

Com a construção da Matriz da Qualidade foi possível identificar as características gerais que precisam ser consideradas ao se desenvolver uma embalagem para uma autopeça.

Quando questionados sobre comunicação entre as áreas, os envolvidos indicaram que houve melhoria entre o setor de desenvolvimento de embalagens e os fornecedores de autopeças.

Com a aplicação do QFD antes da definição das embalagens, as áreas clientes puderam expressar suas necessidades e passaram a ter posição pró-ativa na busca de soluções de problemas no momento da aprovação.

Convém ressaltar que o método foi aplicado em embalagens cujas autopeças não sofreram alteração ao serem desenvolvidas por fornecedores nacionais. Os resultados podem ser aproveitados como "guia" na definição embalagens de novas autopeças ou mesmo na melhoria de embalagens já existentes.

Pode ser observado também que na montadora, o desenvolvimento de produtos tem mais rigor que de embalagens, visto que há um procedimento específico da empresa para novos produtos e que o mesmo não ocorre com embalagens. Com isto, a utilização do método QFD pode contribuir para desenvolvimentos de embalagens, área que geralmente recebe menos atenção nas organizações. 
Como trabalho futuro indica-se acompanhar os usuários e verificar a dificuldades e melhorias que a abordagem de utilização do QFD promoveu.

\begin{abstract}
The aim of this paper is analyze the application of Quality Function Deployment (QFD) in development of packaging for transportation and storage of parts used in the assembly line of an automobile. Although QFD is a tool widely used in the automotive industry for product development, it is not widely used in packaging development. The automotive industry assess packaging used in the components material handling for the approval of new products. Based on the knowledge of people from different areas, which work in the design, development and release packaging, this study shows which parameters are taken into account and the degree of importance among the areas, as example: cost, preserving part, traceability, ergonomics. Several delays in the approval of automotive parts prototype happen because of problems with their packaging. Thus, QFD can help to minimize this problem.
\end{abstract}

Key-words: packaging development; quality function deployment; concurrent engineering.

\title{
Referências
}

AKAO, Y. Quality function deployment: integrating customer requirements into product design. Traduzido por Glenn H. Mazur. Cambridge: Productivity Press, 1990.

ASSOCIAÇÃO BRASILEIRA DE NORMAS TÉCNICAS. NBR ISO 9001:2008 Sistemas de gestão da qualidade Requisitos. Rio de Janeiro, 2008.

B ADIN, N. T. Modelo de Referência para o Processo de Desenvolvimento de Produto Integrando Fornecedores e Baseado nos conceitos de Engenharia Simultânea, Custeio-Alvo e Empresa Virtual. Tese (Doutorado em Engenharia de Produção e Sistemas) - Universidade Federal de Santa Catarina, Florianópolis, 2005.

BALLOU, R. H. Gerenciamento da cadeia de suprimentos: planejamento, organização e logística empresarial. Porto Alegre: Bookman, 2001. 532p

CHAN, L. e WU, M. Quality function deployment: A literature review. European Journal of Operational Research, v. 143, p. 463-497, 2002.

cross ref

CHENG, L. C. e MELO FILHO, L. D. R. QFD: Desdobramento da função qualidade na gestão de desenvolvimento de produtos. São Paulo: Blucher, 2007.

CHENG, L.C. et al QFD: Planejamento da Qualidade, Belo Horizonte: UFMG; Fundação Christiano Ottoni, 1995.

DEROS, B. M.; RAHMAN, N.; RAHMAN, M. N. A.; ISMAIL, A. R.; SAID, A. H. Application of Quality Function Deployment to Study Critical Service Quality Characteristics and Performance Measures. European Journal of Scientific Research, v.33, n.3, p. 398-410, 2009.

GURGEL, F. A. Administração de Embalagens. São Paulo: Thomson Learning, 2007.

HAUSER, J. R., CLAUSING, D. The House of Quality. Harvard Business Review, v. 66, n.3, p. 63-73, mayjun. 1988. 
KANO, N.; SERAKU, N.; TAKAHASHI, F.; TSUJI, S. Attractive quality and must-be quality, Hinshitsu. Quality, The Journal of the Japanese Society for Quality Control, v. 14, n. 2, p. 39-48, 1984.

MEHRJERDI, Y. Z. Quality function deployment and its extensions. International Journal of Quality \& Reliability Management, v. 27, n. 6, p.616-640, 2010.

cross ref

MIGUEL, P. A. C. Implementação do QFD para o Desenvolvimento de Novos Produtos. São Paulo: Atlas, 2008.

Miguel, P. A. C.; CARNEVALli, J. A. Aplicações não-convencionais do desdobramento da função qualidade. São Paulo: Artliber Editora, 2006.

MUNIZ, J. A Utilização da Engenharia Simultânea no Aprimoramento Contínuo e Competitivo das Organizações: Estudo de Caso do modelo usado no Avião EMB 145 da Embraer. 1996, f. 163. Dissertação (Mestrado em Engenharia de Produção) - Escola Politécnica da USP, São Paulo, 1996.

OTELINO, Manoel. A Casa da Qualidade. 1999. Dissertação (Mestrado em Engenharia de Produção) - Universidade de São Paulo, São Carlos, 1999.

PUGH, S. Total design: integrated methods for successful product engineering. Workingham: Addison-Wesley, 1991.

RIBEIRO, J. L. D.; ECHEVESTE, M. E.; DANILEVICZ, A. M. F. A Utilização do QFD na Otimização de Produtos, Processos e Serviços. Porto Alegre: FEENG/PPGEP/EE/UFRGS, 2001.

SUlLIVAN, L. P. Quality Function Deployment. Quality Progress, v. 19, n. 6, p. 39-50, 1986.

WHEELWRIGHT, S.C.; CLARK, K.B. Revolutionizing product development: quantum leaps in speed, efficiency, and quality. New York: Free Press. 1992.

ZHANG, Z. and CHU, X. Fuzzy group decision-making for multi-format and multi-granularity linguistic judgments in Quality Function Deployment. Expert Systems with Applications, v. 36, p. 9150-9158, 2009.

cross ref

\section{Dados dos autores:}

\section{Nome Completo: Byanca Porto de Lima}

Filiação institucional: Universidade de Taubaté - UNITAU - Taubaté - Brasil

Departamento: Engenharia Mecânica

Função ou cargo ocupado: Mestranda

Endereço completo para correspondência (bairro, cidade, estado, país e CEP): Rua Daniel Danelli, s/n - Taubaté- SP - Cep: 12060-440.

Telefones para contato: (12) 3625-4192

e-mail: byanca_porto@yahoo.com.br

\section{Nome Completo: Jorge Muniz Junior}

Filiação institucional: Universidade Estadual Paulista - UNESP - Campus de Guaratinguetá -

Guaratinguetá - Brazil

Departamento: Produção 
Função ou cargo ocupado: Docente

Endereço completo para correspondência (bairro, cidade, estado, país e CEP): Av. Ariberto Pereira da Cunha, 333, Pedregulho, Guaratinguetá, SP- Cep: 12516-410.

Telefones para contato: (12) 3123-2855

e-mail: jorgemuniz@feg.unesp.br

Nome Completo: Antonio Wagner Forti

Filiação institucional: Universidade Estadual Paulista - UNESP - Campus de Guaratinguetá -

Guaratinguetá - Brazil

Departamento: Mecânica

Função ou cargo ocupado: Docente

Endereço completo para correspondência (bairro, cidade, estado, país e CEP): Av. Ariberto Pereira da Cunha, 333, Pedregulho, CEP: 12.516-410 - Guaratinguetá, SP, Brasil.

Telefones para contato: (12) 3123-2218

e-mail: awforti@feg.unesp.br

Recebido em: 26/11/2011

Aceito em: 30/08/2012 